\title{
Foreskin cutting beliefs and practices and the acceptability of male circumcision for HIV prevention in Papua New Guinea
}

David MacLaren ${ }^{1 *}$, Rachael Tommbe ${ }^{2}$, Tracie Mafile' $^{3}$, Clement Manineng $^{4}$, Federica Fregonese ${ }^{5}$, Michelle Redman-MacLaren', Michael Wood ${ }^{6}$, Kelwyn Browne', Reinhold Muller ${ }^{8,9}$, John Kaldor ${ }^{10}$ and William John McBride

\begin{abstract}
Background: Male circumcision (MC) reduces HIV acquisition and is a key public health intervention in settings with high HIV prevalence, heterosexual transmission and low MC rates. In Papua New Guinea (PNG), where HIV prevalence is $0.8 \%$, there is no medical MC program for HIV prevention. There are however many different foreskin cutting practices across the country's 800 language groups. The major form exposes the glans but does not remove the foreskin. This study aimed to describe and quantify foreskin cutting styles, practices and beliefs. It also aimed to assess the acceptability of MC for HIV prevention in PNG.
\end{abstract}

Methods: Cross-sectional multicentre study, at two university campuses (Madang Province and National Capital District) and at two 'rural development' sites (mining site Enga Province; palm-oil plantation in Oro Province). Structured questionnaires were completed by participants originating from all regions of PNG who were resident at each site for study or work.

Results: Questionnaires were completed by 861 men and 519 women. Of men, 47\% reported a longitudinal foreskin cut (cut through the dorsal surface to expose the glans but foreskin not removed); $43 \%$ reported no foreskin cut; and 10\% a circumferential foreskin cut (complete removal). Frequency and type of cut varied significantly by region of origin $(p<.001)$. Most men $(72-82 \%)$ were cut between the ages of $10-20$ years. Longitudinal cuts were most often done in a village by a friend, with circumferential cuts most often done in a clinic by a health professional. Most uncut men (71\%) and longitudinal cut men (84\%) stated they would remove their foreskin if it reduced the risk of HIV infection. More than $95 \%$ of uncut men and $97 \%$ of longitudinal cut men would prefer the procedure in a clinic or hospital. Most men (90\%) and women (74\%) stated they would remove the foreskin of their son if it reduced the risk of HIV infection.

Conclusion: Although 57\% of men reported some form of foreskin cut only $10 \%$ reported the complete removal of the foreskin, the procedure on which international HIV prevention strategies are based. The acceptability of MC (complete foreskin removal) is high among men (for themselves and their sons) and women (for their sons). Potential MC services need to be responsive to the diversity of beliefs and practices and consider health system constraints. A concerted research effort to investigate the potential protective effects of longitudinal cuts for HIV acquisition is essential given the scale of longitudinal cuts in PNG.

Keywords: Male circumcision, Acceptability, Foreskin cutting, Papua New Guinea, HIV, Prevention, Beliefs, Foreskin cutting practices, Longitudinal Foreskin cut, Circumferential Foreskin cut

\footnotetext{
*Correspondence: david.maclaren@jcu.edu.au

'School of Medicine and Dentistry, James Cook University, McGregor Road, Smithfield, Cairns 4878, Queensland, Australia

Full list of author information is available at the end of the article
} 


\section{Background}

Male circumcision (MC), or the surgical removal of the foreskin, has received intense public health attention since three large randomised trials, published between 2005 and 2007, reported that the procedure can reduce male susceptibility to heterosexual acquisition of HIV by approximately $60 \%$ [1-3]. These results confirmed earlier observational studies that documented an association between lower HIV infection rates and MC [4,5]. In 2007 it was estimated that up to 5.7 million new HIV infections could be averted over 20 years through the implementation of MC services in sub-Saharan Africa [6-8]. WHO and UNAIDS now recommend MC programs be included in comprehensive HIV prevention packages in settings of high HIV prevalence with heterosexual transmission and low MC rates [9].

MC for HIV prevention is viewed favourably across numerous high HIV prevalence settings in East and Southern Africa, both in traditionally circumcising and non-circumcising communities [10-21]. MC programs are now being implemented across this region, accompanied by ongoing acceptability studies [12,22-35]. However, a detailed understanding of local social, cultural, gender, religious and medical issues must underpin such MC programs [36-39].

MC may also play an important public health role in moderate HIV prevalence countries. However very few investigations of MC's acceptability, feasibility and epidemiological impact have been conducted in such settings [40-46]. Papua New Guinea (PNG), the largest South Pacific Island country, has the second highest HIV prevalence of the Asia-Pacific region (after Thailand). In 2012 PNG had an estimated adult HIV seroprevalence of $0.79 \%$ (15-49 years), associated with widespread behavioural risk and high rates of sexually transmitted infections [47-49]. More females than males are infected with HIV, suggesting heterosexual intercourse as the primary driver. The PNG health system does not provide routine $\mathrm{MC}$ services. Investigating $\mathrm{MC}$ for HIV prevention is a current research priority for the PNG National AIDS Council [50].

PNG has extreme social, cultural and geographical diversity. PNG's 7.1 million people speak over 800 distinct languages and live in different settings: from villages on remote coral atolls to highland valleys to regional and provincial towns and their associated peri-urban squatter settlements. Reflecting this diversity, HIV prevalence is unevenly distributed: Highlands and Southern Regions have $0.89 \%$ and $0.88 \%$ respectively and Momase and New Guinea Islands Regions $0.66 \%$ and $0.58 \%$ respectively [47]. PNG's unparalleled diversity means national HIV policy formulation is complex and requires evidence from a wide range of studies [51,52].
The context of MC in PNG is also complex. Most cultural groups do not traditionally practice $\mathrm{MC}$, however there is a wide variety of foreskin cutting practices across the country [53,54]. The full removal of the foreskin, commonly referred to as a 'round cut', is produced by a circumferential cut to the foreskin and produces results equivalent to medical MC. Local variations, with many local descriptive names, are produced by a longitudinal cut along the dorsal surface of the foreskin. This exposes the glans penis and leaves the foreskin hanging loose beneath the penis. These variations are often generically referred to as 'straight cut' or 'split'. Most of these cuts take place in the community with few occurring through the formal health system [55-57]. The rich ethnographic and anthropological record in PNG has detailed descriptions of initiation and blood-letting rituals in some cultural groups that involve multiple cuts to the foreskin and penis [58-60].

In recent years there appears to have been a shift in foreskin cutting practices in PNG that have paralleled dramatic social, economic and religious change $[54,60]$. A National HIV/AIDS Behavioural Surveillance Study in 2006 documented 26 - 70\% of men had some form of foreskin cut, however the study did not differentiate between the 'round cut' or 'straight cut' [61]. More recent studies have made the distinction $[62,63]$ and found 25 $50 \%$ of men had some form of foreskin cut, with considerable diversity in the extent and type of foreskin cut reported. Qualitative studies are expanding knowledge about beliefs and practices of the various styles of foreskin cutting, and their implications for HIV prevention in PNG $[45,46,57]$. Men in these studies were generally in favour of MC being introduced for HIV prevention, but women were cautious or not in favour because of cultural and religious concerns and fear of sexual disinhibition of husbands or partners $[45,46]$. Building on these studies, it was important to quantify the diversity of foreskin cutting styles, practices and beliefs in PNG and assess the proportion of men and women who may find MC acceptable for HIV prevention.

This paper reports on the collaborative 'Acceptability of Male Circumcision for HIV Prevention in PNG' study carried out from July 2010 to February 2011. Here we report quantitative results for two objectives of the study: (i) describe and categorise male genital cutting, which includes $\mathrm{MC}$; to ii) examine social, cultural and religious practices and their influence on the acceptability of MC for HIV prevention.

\section{Methods}

This was an observational cross-sectional study, conducted in collaboration between researchers from Papua New Guinean and Australian universities and partnering with companies at two 'rural development' sites. 


\section{Participants}

The study was undertaken at four sites in four provinces: (i) Pacific Adventist University (PAU), Port Moresby, National Capital District; (ii) Divine Word University (DWU), Madang, Madang Province; (iii) Higaturu Oil Palms, Popondetta, Oro Province; and (iv) Porgera Joint Venture, Porgera, Enga Province. The first two sites are major universities that have predominantly residential student bodies. The latter two are a major oil palm production facility on the coastal plains and a major gold mine in the highlands. Sites were chosen to provide access to a wide a variety of socio-cultural, geographic, religious and educational backgrounds. All four sites attract people from across all PNG regions and most cultural backgrounds, to study or work. Key collaborators at each site had also been involved with previous HIV research or prevention programs.

A sample of 200 men per site was necessary for a precision of at least $5 \%$ to estimate the prevalence of male circumcision in a range of $5-50 \%$. Further, a sample of 100 women per site was deemed feasible to collect data on women's social, cultural and religious perspectives of foreskin cutting and the acceptability of MC for HIV prevention. Therefore, considering possible $20 \%$ attrition, at each site 250 males and 175 female were invited to enrol. At the two university campuses students were selected via a systematic sampling approach (by alphabetised student lists). Blank envelopes containing self-administered questionnaires were given to the selected students via regional student group leaders. At the two rural development sites men and women who attended the health centre for routine workplace health and safety checks or minor health issues were invited to participate sequentially, until the targeted sample size was reached and allowing for recruitment gaps if researchers were still engaged in assisting previous participants with the questionnaire. To achieve the sample size in women, recruitment also took place by inviting all women employed in selected company departments to participate.

\section{Questionnaires}

The structured questionnaire contained eight sections and covered demographics, province of origin, knowledge and attitudes, sexual history and foreskin cutting/ penile modification. Both closed and open ended questions were used. Questionnaires were offered in English or Tok Pisin (PNG lingua franca) for use in rural sites. The questionnaire had an information sheet attached that clearly stated that participation was voluntary and to complete and return the questionnaire meant consent was given for results to be used in the study. The male questionnaire contained a seven level classification of foreskin cutting. A photograph accompanied the written description for each of the seven foreskin cutting types with the statement 'please circle the number beside the picture that looks most like your own foreskin'. See Additional file 1: Figure S1 for male questionnaire in English and Additional file 2: Figure S2 for female questionnaire in English. Questionnaires were generally selfadministered but assistance was rendered at rural sites by a researcher of the same sex if literacy skills did not allow for self-administration. In addition to questionnaires, individual interviews and focus groups discussions were conducted. Findings from these qualitative methods will be published separately.

\section{Data handling and analysis}

Collected questionnaires were collated and data were entered into an Excel spreadsheet which was subsequently imported into the statistical package SPSS (Version 20) for analysis. The actual data analysis was preceded by extensive plausibility checks and data cleaning procedures. $\mathrm{Nu}$ merical information was summarized as percentages or mean and standard deviation or median and inter-quartile range. Bivariate analyses were undertaken by employing exact versions of standard test procedures such as exact binomial test of two categorical variables. Non parametric Kruskal-Wallis tests were used for comparison of numerical values between behavioural categories since the underlying distributions proved to be skewed.

\section{Ethics}

Ethics clearance was granted by Human Research Ethics Committees of Pacific Adventist University, Divine Word University, James Cook University (Australia) and Papua New Guinea National AIDS Council. Endorsement was also provided by the Provincial AIDS Committees of the National Capital District and Oro, Enga and Madang Provinces.

Results were provided to institutions, key stakeholders and participants during interactive workshops at the four study sites between Oct 2011 and March 2012.

\section{Results}

\section{Demographic characteristics of study population}

The structured questionnaire was completed by a total of 1,380 participants (861 men and 519 women) at the four sites. DWU contributed $24 \%(\mathrm{n}=208)$ of men to the sample; PAU 24\% $(n=204)$; Porgera 26\% $(n=227)$ and Popondetta $26 \%(n=222)$. For women, the respective proportions were DWU 20\% ( $n=103)$; PAU 30\% ( $n=157)$; Porgera 30\% ( $n=158)$ and Popondetta 20\% $(n=101)$. Overall, age in men ranged from 18-65 years (median 25 IQR 21-32) and in women from 18-58 (median 24 IQR 21-30). The majority of participants at PAU and DWU were under 25 years of age (77\% and $77 \%$ of men; $91 \%$ and $80 \%$ of women respectively). The majority of participants at Porgera and Popondetta were 25 year or older $(88 \%$ and 
$63 \%$ of men; $82 \%$ and $75 \%$ of women respectively). Region of origin in the overall sample was distributed as follows: Highlands (men 47\%; women 42\%); Southern (men 27\%; women 28\%); Momase (men 18\%; women 14\%); New Guinea Islands (men 8\%; women 16\%) and reflects regional distribution from 2011 national population census (Highlands 43\%; Momase 25\%; Southern 19\%; New Guinea Islands 14\%) [64]. More details on socio-demographic information by Region of Origin are presented in Table 1.

\section{Prevalence of foreskin cuts}

Ninety-nine percent of men $(854 / 861)$ provided data on foreskin cutting: $10 \%(n=87)$ reported a circumferential cut; $47 \%(n=398)$ reported some form of longitudinal cut, and $43 \%(n=369)$ no cut at all. The cutting varied significantly with age, education and region of origin (Table 2). Longitudinal cut was most frequent in men from Momase (58\% of all men from that region); circumferential cut most frequent in men from New Guinea Islands (24\%) and an uncut foreskin was most frequent in men from the Southern (50\%) and Highlands $(47 \%)$ regions $(\mathrm{p}<0.001)$ (Table 3$)$. Five variations or styles of longitudinal cut were recorded and varied by region of origin (Table 3 ).

\section{Circumstances of foreskin cutting}

Most cut men (82\% longitudinal cut men; $72 \%$ circumferential cut men) reported having their foreskin cut between the ages of 10 and 20, with mean age 17 years (SD 4.77; Range 2-38) at longitudinal and 15 years (SD 6.66; Range $1-30)$ at circumferential cut $(\mathrm{p}<0.001)$. The place and person performing the cuts varied significantly between longitudinal and round cut $(\mathrm{p}<0.001)$. Longitudinal cuts were most frequently done in the village by a friend. Round cuts were most frequently done in a clinic by a health professional. Razors and surgical blades were the most utilized tools in all cuts (>90\%), with scissors or bamboo used for $6 \%$ of circumferential cuts and a needle and rubber used for $5 \%$ of longitudinal cuts. For more details on place, person and tool used for foreskin cutting see Figure 1.

\section{Attitudes and beliefs about foreskin cutting}

Attitudes and beliefs about foreskin cutting were investigated with both men and women around five thematic areas: (i) foreskin cutting and socio-cultural practice; (ii) foreskin cutting and sexual practice; (iii) foreskin cutting and sexual health; (iv) safety of foreskin cutting; (v) foreskin cutting and socio-cultural belief. Statements that participants responded to (yes, no, unsure) in each theme were deliberately mixed on the original questionnaire, however results are presented here in the five thematic areas. Responses to statements by uncut men, longitudinal cut men, circumferential cut men, all men and all women are given in Table 4.

Key findings for (i) Foreskin cutting and sociocultural practice: Most men (63\%) stated that foreskin cutting was not a part of their cultural practice/tradition. For women $42 \%$ stated it was not their cultural practice/ tradition, although half (51\%) were unsure. Around a third of men and less than one in five women agreed that having a cut foreskin proves manhood. Less than $20 \%$ of men and women stated that foreskin cutting was forbidden by their custom/tradition or by their religion.

Key findings for (ii) foreskin cutting and sexual practice: A third of men and around $20 \%$ of women agreed that having a cut foreskin encourages men to have more sexual partners. Less than $15 \%$ of men and $10 \%$ of women agreed that having a cut foreskin decreases sexual pleasure for men with about half of men and the majority of women responding they were unsure. Around a third of men and one in ten women agreed to the statement that sex lasts longer for men with a cut foreskin. More than $40 \%$ of men but less than $20 \%$ of women agreed to the statement that women prefer to have sex with man with cut foreskin; half of men and almost three-quarters of women responded they were unsure.

Key findings for (iii) foreskin cutting and sexual health: More than half of men and a little under half of women agreed that men with a cut foreskin can become infected with HIV. Around a third of men and women agreed that having a cut foreskin reduces the risk of becoming infected with HIV. The majority of both men (57\%) and women (51\%) disagreed with the statement that men with a cut foreskin do not need to use condoms to protect from STI and HIV.

Key findings for (iv) safety of foreskin cutting: Around $10 \%$ of men and $5 \%$ of women agreed that foreskin cutting in a village by a friend or relative was a safe procedure. Almost all men and three quarters of women disagreed that it is safe to use the same blade or razor to cut the foreskin of many men at one time. Most men $(88 \%)$ and women $(71 \%)$ agreed that having a foreskin cut by a health professional in a health facility is a safe procedure.

Key findings for (v) foreskin cutting and sociocultural beliefs: A quarter of men agreed that allowing the blood to flow when the foreskin is cut is important in their culture/custom. The majority of men agreed that it was important to eat special food and to reduce the amount of water in the days following the cut. More than $80 \%$ of men agreed that men need to stay away from women after having a foreskin cut. Around $40 \%$ of men agreed that a cut foreskin makes a man's body grow strong and the penis grow bigger; less than 20\% women agreed, with the majority unsure. 
Table 1 Demographic characteristics by region of origin

\begin{tabular}{|c|c|c|c|c|c|c|c|c|}
\hline \multirow[t]{4}{*}{ Characteristic^ } & \multirow{2}{*}{\multicolumn{2}{|c|}{$\begin{array}{c}\text { New Guinea Islands } \\
\%(\mathbf{n})\end{array}$}} & \multirow{2}{*}{\multicolumn{2}{|c|}{$\begin{array}{c}\text { Momase } \\
\%(n)\end{array}$}} & \multirow{2}{*}{\multicolumn{2}{|c|}{$\begin{array}{c}\text { Southern } \\
\%(n)\end{array}$}} & \multirow{2}{*}{\multicolumn{2}{|c|}{$\begin{array}{c}\text { Highlands } \\
\%(n)\end{array}$}} \\
\hline & & & & & & & & \\
\hline & Male & Female & Male & Female & Male & Female & Male & Female \\
\hline & $n=72$ & $\mathrm{n}=\mathbf{8 0}$ & $n=153$ & $n=72$ & $n=230$ & $n=146$ & $n=402$ & $\mathrm{n}=\mathbf{2 1 8}$ \\
\hline \multicolumn{9}{|l|}{ Age } \\
\hline Under 25 & $50.8(32)$ & $66.2(51)$ & $61.9(91)$ & $70.6(48)$ & $48.1(104)$ & $48.9(68)$ & 45.9 (168) & $47.4(91)$ \\
\hline 25 and over & $49.2(31)$ & $33.8(26)$ & $38.1(56)$ & $29.4(20)$ & $51.9(112)$ & $51.1(71)$ & $54.1(198)$ & $52.6(101)$ \\
\hline \multicolumn{9}{|l|}{ Site } \\
\hline DWU & $31.9(23)$ & $27.5(22)$ & $35.9(55)$ & $38.9(28)$ & $12.2(28)$ & $17.8(26)$ & $25.1(101)$ & $12.4(27)$ \\
\hline PAU & $45.8(33)$ & $56.3(45)$ & $25.5(39)$ & $33.3(24)$ & $18.7(43)$ & $19.9(29)$ & $21.6(87)$ & $26.6(58)$ \\
\hline Porgera & $16.7(12)$ & $8.8(7)$ & $10.5(16)$ & $12.5(9)$ & $5.2(12)$ & $6.2(9)$ & $46.5(187)$ & $60.6(132)$ \\
\hline Popondetta & $5.6(4)$ & $7.5(6)$ & $28.1(43)$ & $15.3(11)$ & $63.9(147)$ & $56.2(82)$ & $6.7(27)$ & $0.5(1)$ \\
\hline \multicolumn{9}{|l|}{ Marital status } \\
\hline Single & $70.8(51)$ & $72.5(58)$ & $71.9(110)$ & $81.9(59)$ & $56.5(130)$ & $44.8(65)$ & $55.7(224)$ & $45.9(100)$ \\
\hline Married & $27.8(20)$ & $21.3(17)$ & $26.8(41)$ & $15.3(11)$ & $40.9(94)$ & $49.7(72)$ & $42.3(170)$ & $44(96)$ \\
\hline Separated/Divorced & $1.4(1)$ & $6.3(5)$ & $1.4(2)$ & $2.8(2)$ & $2.6(6)$ & $5.6(8)$ & $1.9(8)$ & $10.1(22)$ \\
\hline \multicolumn{9}{|l|}{ Religion } \\
\hline Anglican & $1.4(1)$ & $0(0)$ & $6.3(6)$ & $1.4(1)$ & $36.1(83)$ & $27.4(40)$ & $0.5(2)$ & $0(0)$ \\
\hline Catholic & $31.9(23)$ & $22.5(18)$ & $21.1(32)$ & $18.3(13)$ & $6.1(14)$ & $9.6(14)$ & $14.4(58)$ & $7.4(16)$ \\
\hline Lutheran & $0(0)$ & $0(0)$ & $28.3(43)$ & $18.3(13)$ & $1.7(4)$ & $3.4(5)$ & $13.7(55)$ & $4.6(10)$ \\
\hline Pentecostal & $8.3(6)$ & $10(8)$ & $24(15.8)$ & $16(22.5)$ & $27.4(63)$ & $23.3(34)$ & $24.1(97)$ & $33.2(72)$ \\
\hline Seventh day Adventist & $45.8(33)$ & $55(44)$ & $23.6(40)$ & $33.8(24)$ & $16.5(38)$ & $20.5(30)$ & $37.3(150)$ & $51.2(111)$ \\
\hline Other & $12.5(9)$ & $12.5(10)$ & $3.3(5)$ & $5.6(4)$ & $11.7(27)$ & $15.8(23)$ & $8.7(35)$ & 3.7 (8) \\
\hline None & $0(0)$ & $0(0)$ & $1.3(2)$ & $0(0)$ & $0.4(1)$ & $0(0)$ & $1.2(5)$ & $0(0)$ \\
\hline \multicolumn{9}{|l|}{ Education } \\
\hline Primary School or less & $2.8(2)$ & $0(0)$ & $22.5(34)$ & $8.7(6)$ & $45.9(105)$ & $25(36)$ & $21.8(87)$ & $6.6(14)$ \\
\hline High/Secondary & $36.1(26)$ & $75(57)$ & $23.8(36)$ & $75.4(52)$ & $32.8(75)$ & $54.9(79)$ & $34.3(137)$ & $58.7(125)$ \\
\hline Voc/Tech college & $18.1(13)$ & $11.8(9)$ & $12.6(19)$ & $8.7(6)$ & $6.1(14)$ & $12.5(18)$ & $13.0(52)$ & 28. (61) \\
\hline University & $43.1(31)$ & $13.2(10)$ & $41.1(62)$ & $7.2(5)$ & $15.3(35)$ & $7.6(11)$ & $31.0(124)$ & $6.1(13)$ \\
\hline \multicolumn{9}{|l|}{ Money earned by } \\
\hline Subsistence & $1.5(1)$ & $13(1)$ & $4.9(7)$ & $9.4(6)$ & $15.5(35)$ & $14.1(19)$ & $9.0(35)$ & $5.3(11)$ \\
\hline Formal employment & $37.3(25)$ & $27.3(21)$ & $38.7(55)$ & $14.1(9)$ & $51.3(116)$ & $43.7(59)$ & $61.5(205)$ & $57.4(120)$ \\
\hline Dependent on family & $46.3(31)$ & $70.1(54)$ & $51.4(73)$ & $70.3(45)$ & $29.2(66)$ & $41.5(56)$ & $95.4(132)$ & $34.4(72)$ \\
\hline Student scholarship & $14.9(10)$ & $1.3(1)$ & $4.9(7)$ & $6.3(4)$ & $4.0(9)$ & $0.7(1)$ & $4.6(18)$ & $2.9(6)$ \\
\hline \multicolumn{9}{|l|}{ Number of wives\# } \\
\hline 0 & $70.8(51)$ & & $73.7(112)$ & & $59.4(136)$ & & $56.5(227)$ & \\
\hline 1 & $29.2(21)$ & $66.6(10)$ & $25.7(39)$ & $66.6(6)$ & $37.1(85)$ & $82.5(47)$ & $31.3(126)$ & $67.7(63)$ \\
\hline More than 1 & $0(0)$ & $33.3(5)$ & $0.7(1)$ & $33.3(3)$ & $3.5(8)$ & $17.5(10)$ & $12.3(49)$ & $32.3(30)$ \\
\hline \multicolumn{9}{|l|}{ Number of Children } \\
\hline 0 & $73.6(53)$ & $75(60)$ & $76.3(116)$ & $80.6(58)$ & $62.0(142)$ & $82.5(66)$ & $576(230)$ & $50(109)$ \\
\hline 1 & $4.2(3)$ & $6.3(5)$ & $7.2(11)$ & $1.4(1)$ & $5.7(13)$ & $11.0(16)$ & $7.3(29)$ & $12.4(27)$ \\
\hline More than 1 & $22.2(16)$ & $18.7(15)$ & $16.4(25)$ & $18(13)$ & $32.3(74)$ & $43.5(66)$ & $35.1(140)$ & $37.6(82)$ \\
\hline
\end{tabular}

\footnotetext{
${ }^{\wedge}$ Totals are not the same for all characteristics. Some participants did not answer all questions.
}

\# For females - number of wives their husband is married to. 
Table 2 Demographic characteristics by foreskin cutting type

\begin{tabular}{|c|c|c|c|c|c|}
\hline & Uncut \% (n) & Longitudinal cut \% (n) & Circumferential cut \% (n) & All men $(n)$ & p-value \\
\hline Overall Sample & $43.2(369)$ & $46.6(398)$ & $10.2(87)$ & 854 & $<.001$ \\
\hline \multicolumn{6}{|l|}{ Age } \\
\hline Under 25 & $34.8(136)$ & $55.5(217)$ & $9.7(38)$ & 391 & \multirow[t]{2}{*}{$<.001$} \\
\hline 25 and Over & $53.0(210)$ & $36.6(145)$ & $10.4(41)$ & 396 & \\
\hline \multicolumn{6}{|l|}{ Site } \\
\hline DWU & $37.7(78)$ & $49.8(103)$ & $12.6(26)$ & 207 & \multirow[t]{4}{*}{$<.001$} \\
\hline PAU & $31.3(62)$ & $53.0(105)$ & $15.7(31)$ & 198 & \\
\hline Porgera & $58.6(133)$ & $34.8(79)$ & $6.6(15)$ & 227 & \\
\hline Popondetta & $43.2(96)$ & $50.0(111)$ & $6.8(15)$ & 222 & \\
\hline \multicolumn{6}{|l|}{ Region } \\
\hline New Guinea Islands & $26.5(18)$ & $50.0(34)$ & $23.5(16)$ & 68 & \multirow[t]{4}{*}{$<.001$} \\
\hline Highlands & $47.4(190)$ & $44.1(177)$ & $8.5(34)$ & 401 & \\
\hline Momase & $28.8(44)$ & $58.2(89)$ & $13.1(20)$ & 153 & \\
\hline Southern & $50.4(115)$ & $42.1(96)$ & $7.5(17)$ & 228 & \\
\hline \multicolumn{6}{|l|}{ Marital Status } \\
\hline Single & $35.1(180)$ & $54.0(277)$ & $10.9(56)$ & 513 & \multirow[t]{3}{*}{$<.001$} \\
\hline Married & $56.5(183)$ & $34.3(111)$ & $9.3(30)$ & 324 & \\
\hline Separated/Divorced & $35.3(6)$ & $58.8(10)$ & $5.9(1)$ & 17 & \\
\hline \multicolumn{6}{|l|}{ Religion } \\
\hline Anglican & $47.8(44)$ & $45.7(42)$ & $6.5(6)$ & 92 & \multirow[t]{7}{*}{$<.05$} \\
\hline Catholic & $48.4(62)$ & $42.2(54)$ & $9.4(12)$ & 128 & \\
\hline Lutheran & $40.2(41)$ & $47.1(48)$ & $12.7(13)$ & 102 & \\
\hline Pentecostal & $42.9(81)$ & $49.2(93)$ & $7.9(15)$ & 189 & \\
\hline Seventh day Adventist & $35.5(92)$ & $50.6(131)$ & $13.9(36)$ & 259 & \\
\hline Other & $58.1(43)$ & $35.1(26)$ & $6.8(5)$ & 74 & \\
\hline None & $62.5(5)$ & $37.5(3)$ & $0.0(0)$ & 8 & \\
\hline \multicolumn{6}{|l|}{ Education } \\
\hline Primary School or less & $52.8(121)$ & $42.8(98)$ & $4.4(10)$ & 229 & \multirow[t]{4}{*}{$<.001$} \\
\hline High/Secondary & $45.2(122)$ & $44.4(120)$ & $10.4(28)$ & 270 & \\
\hline Vocational/College & $38.1(37)$ & $48.5(47)$ & $13.4(13)$ & 97 & \\
\hline University & $34.4(87)$ & $51.4(130)$ & $14.2(36)$ & 253 & \\
\hline \multicolumn{6}{|l|}{ Money earned by } \\
\hline Subsistence & $37.2(29)$ & $47.4(37)$ & $15.4(12)$ & 78 & \multirow[t]{4}{*}{$<.001$} \\
\hline Formal employment & $51.9(208)$ & $38.2(153)$ & $10.0(40)$ & 401 & \\
\hline Dependent on family & $37.1(111)$ & $53.2(159)$ & $9.7(29)$ & 299 & \\
\hline Student Scholarship & $25.0(11)$ & $63.6(28)$ & $11.4(5)$ & 44 & \\
\hline \multicolumn{6}{|l|}{ Number of Wives } \\
\hline 0 & $35.1(184)$ & $54.0(283)$ & $10.9(57)$ & 524 & \multirow[t]{3}{*}{$<.001$} \\
\hline 1 & $51.9(140)$ & $37.4(101)$ & $10.7(29)$ & 270 & \\
\hline$>1$ & $74.1(43)$ & $24.1(14)$ & $1.7(1)$ & 58 & \\
\hline \multicolumn{6}{|l|}{ Number of Children } \\
\hline 0 & $35.8(193)$ & $53.4(288)$ & $10.8(58)$ & 539 & \multirow[t]{3}{*}{$<.001$} \\
\hline 1 & $44.6(25)$ & $44.6(25)$ & $10.7(6)$ & 56 & \\
\hline$>1$ & $57.5(146)$ & $33.5(85)$ & $9.1(23)$ & 254 & \\
\hline
\end{tabular}


Table 3 Foreskin cutting classification by region of origin

\begin{tabular}{|c|c|c|c|c|c|c|}
\hline & $\begin{array}{l}\text { New Guinea } \\
\text { Islands }\end{array}$ & Highlands & Momase & Southern & $A L L \wedge$ & $p$-value \\
\hline & $\%(n)$ & $\%(n)$ & $\%(n)$ & $\%(n)$ & $\%(n)$ & \\
\hline \multicolumn{7}{|c|}{ Overall foreskin cutting classification } \\
\hline Uncut & $26(18)$ & $47(190)$ & $29(44)$ & $50(115)$ & 43 (369) & $<.001$ \\
\hline Longitudinal cut & $50(34)$ & $44(177)$ & $58(89)$ & $42(96)$ & 47 (398) & \\
\hline Circumferential cut & $24(16)$ & $9(34)$ & $13(20)$ & $7(17)$ & $10(87)$ & \\
\hline \multicolumn{7}{|l|}{ Longitudinal foreskin cut variations } \\
\hline Longitudinal Cut: Variation (i) & $19(13)$ & $16(66)$ & $20(31)$ & $16(37)$ & $17(147)$ & \\
\hline \multicolumn{7}{|c|}{ Foreskin has been cut but still partially covers the head of the penis } \\
\hline Longitudinal Cut: Variation (ii) & $25(17)$ & $24(96)$ & $32(49)$ & $20(46)$ & $25(208)$ & \\
\hline \multicolumn{7}{|c|}{ Foreskin has been cut and remains loose behind the head of the penis } \\
\hline Longitudinal Cut: Variation (ii) & $2(1)$ & $2(6)$ & $3(5)$ & $2(5)$ & $2(17)$ & \\
\hline \multicolumn{7}{|c|}{ Foreskin has been cut on both sides leaving two or more tags } \\
\hline Longitudinal Cut: Variation (iv) & $3(2)$ & $1(3)$ & $2(3)$ & $1(2)$ & $1(10)$ & \\
\hline \multicolumn{7}{|c|}{ Foreskin has been cut with scarring along the penis } \\
\hline Longitudinal Cut: Variation (v) & $2(1)$ & $2(6)$ & $1(1)$ & $3(6)$ & $2(14)$ & \\
\hline $\begin{array}{l}\text { 'Cowboy cut' where foreskin can } \\
\text { the penis }\end{array}$ & & & & & & \\
\hline
\end{tabular}

\section{Foreskin cutting and sexual practice}

Men with circumferential cut had significantly fewer lifetime female sexual partners (median 5) compared to the men with longitudinal cut (6) or uncut men (7) $(\mathrm{p}<$ $0.05)$. There was no difference in condom use at last female sex between circumferential cut, longitudinal cut and uncut men $(35 \%, 32 \%$ and $33 \%$ respectively; $\mathrm{p}=0.9)$.

\section{Acceptability of male circumcision}

Most uncut men and longitudinal cut men stated they would remove their foreskin or its remnant part, if it reduced the risk of HIV infection (71\% and 76\%) or if it had an overall health benefit (84\% and $88 \%$ ) (Table 5). The vast majority would prefer the procedure done in a formal health facility by a health worker. Almost twothirds (64\%) of uncut men and half (51\%) of longitudinal cut men stated they were planning to have their foreskin removed at some time in the future (Table 5).

Almost all men and three-quarters of women (74\%) stated they would remove the foreskin of their male child if it reduced the risk of HIV infection, and even higher proportions if it had an overall health benefit (Table 5).

\section{Discussion}

This is the first study conducted in PNG that combines the investigation of prevalence, beliefs, attitudes and practices about foreskin cutting and the acceptability of male circumcision. It thus addresses a vital area for public health and HIV prevention in the country. Results expand the evidence vital for the National AIDS Council, National Department of Health and other policy makers to more effectively plan HIV prevention strategies.

The overall prevalence of foreskin cutting in the study was $57 \%$, however only $10 \%$ of men reported the complete removal of the foreskin, the procedure on which international HIV prevention strategies and recommendations are based upon. The prevalence of foreskin cutting in this study was higher than the $25.8 \%$ longitudinal cut and $3.4 \%$ circumferential cut documented in recent studies in plantation workers in the Highlands region, but similar to studies in the national capital [61-63,65]. The deliberate approach to include participants from diverse geographic locations and cultural backgrounds allowed a sample with a similar regional proportionality to the PNG population. Although this does not automatically imply representativeness or generalisability across the PNG population, this characteristic does enable closer analysis of the diversity of opinions and experience. The highest prevalence of both longitudinal and circumferential cuts in this study were from men from New Guinea Islands and Momase. This was not surprising given the numerous cultural groups with a tradition of foreskin cutting in these regions. However around half of men from the Highlands and Southern regions also reported having a cut foreskin (most often longitudinal cut). This was surprising given 

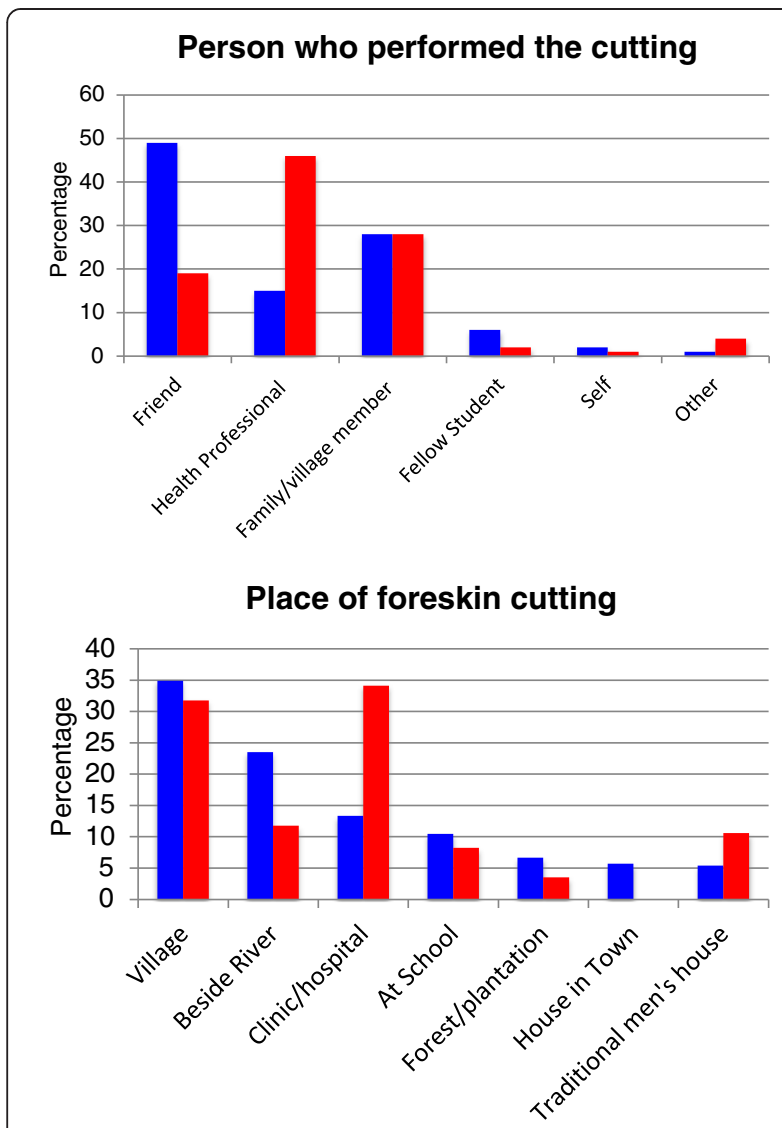

Tool used for cutting

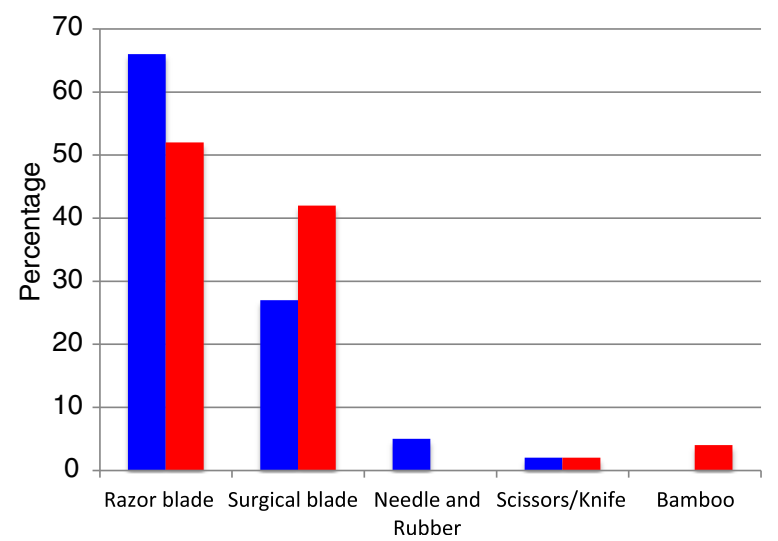

Figure 1 Place, person and tool used for foreskin cutting for men with longitudinal cut (in blue) and circumferential cut (in red).

there are far fewer cultural groups with a tradition of foreskin cutting in these regions. Older men from Highlands and Southern regions were less likely to have a foreskin cut, or have detailed knowledge about foreskin cutting. This reflects recent rapid changes that enable modern education, travel and work practices that facilitate the exchange of knowledge, beliefs and practices, including foreskin cutting.
This study provides further evidence that longitudinal cuts are the major forms of foreskin cutting in PNG $[54,57,66,67]$. Of men with dorsal longitudinal cuts in this study, more than half reported a variant where the glans penis is totally exposed. In this variant, the remnant foreskin hangs loosely on the ventral surface of the penis permanently exposing the inner surface of the foreskin. The foreskin then reduces in size, becomes dry and is visually similar to the outer surface of the foreskin. In some men with this variant, the foreskin reduces to such an extent that the penis appears very similar to a circumcised penis (See Figure 2). It is unclear what the implications of such longitudinal cuts are for HIV prevention. The major explanation of how MC protects against HIV is that the inner aspect of the foreskin is the prime site for HIV entry on the penis. The inner aspect (and the frenulum) have a thinner keratin layer than the glans or penile shaft and so enable HIV entry to Langerhans cells which carry specific HIV receptors [68]. Removing the foreskin through $\mathrm{MC}$ removes the prime site for HIV entry and so reduces the risk of HIV infection. This leads to the potential that changes to the exposed inner surface and reduction in the surface area of the remnant foreskin may provide some protection against HIV infection for men with this variant. However the potential protective effect is currently unknown $[57,69]$. A concerted research effort to investigate the potential protective effects of longitudinal cuts for HIV acquisition in PNG is essential given the scale of longitudinal cuts documented. This is particularly important given that most of the foreskin cutting does not occur within traditional initiation rituals or within the formal health sector, but predominantly between peers as an evolving contemporary socio-cultural practice. Moreover, many men with longitudinal cuts in PNG consider themselves as 'circumcised' because of the appearance of their penis and because the commonly used Tok Pisin terms katim skin bilong kok or katim kok do not differentiate between longitudinally cut or totally removed foreskin [46]. Studies from PNG, Rwanda, Swaziland and Kenya have highlighted regional and cultural variations of foreskin cutting that do not completely remove the foreskin, and that many of these men consider themselves 'circumcised'. This re-enforces the need for further research and more nuanced understanding of MC for HIV prevention in such settings $[33,57,70,71]$. This is particularly important given cultural contexts are constantly evolving and adapting to new influences and circumstances [72].

$\mathrm{MC}$ for adult men was viewed positively. Three quarters of uncut men $(76 \%)$ stated that they would remove their foreskin if it had a health benefit and $71 \%$ if it reduced the risk of HIV infection. These results reflect similarly high proportions (86\%) of male university students willing to have the foreskin removed in a pilot 
Table 4 Attitudes and beliefs about foreskin cutting

\begin{tabular}{|c|c|c|c|c|c|c|c|c|}
\hline & & $\begin{array}{c}\text { Uncut } \\
\text { men \% (n) }\end{array}$ & $\begin{array}{l}\text { Longitudinal cut } \\
\text { men } \%(n)\end{array}$ & $\begin{array}{c}\text { Circumferential cut men } \\
\%(n)\end{array}$ & $\begin{array}{l}p \text {-value } \\
\text { men }\end{array}$ & $\begin{array}{l}\text { All men } \\
\%(n)\end{array}$ & $\begin{array}{l}\text { Women } \\
\%(n)\end{array}$ & $\begin{array}{l}\text { p-value men } \\
\text { and women }\end{array}$ \\
\hline \multicolumn{9}{|l|}{ Theme (i) Foreskin cutting and socio-cultural practice } \\
\hline \multirow[t]{3}{*}{ Having a split foreskin is a part of my culture } & Yes & $9 \%(32)$ & $25 \%(97)$ & $24 \%(21)$ & \multirow[t]{3}{*}{$<.001$} & $18 \%(150)$ & $8 \%(37)$ & \multirow[t]{3}{*}{$<.001$} \\
\hline & No & $68 \%(246)$ & $57 \%(222)$ & $60 \%(52)$ & & $62 \%(520)$ & $42 \%(204)$ & \\
\hline & Unsure & $23 \%(85)$ & $19 \%(73)$ & $16 \%(14)$ & & $20 \%(172)$ & $51 \%(248)$ & \\
\hline \multirow[t]{3}{*}{ Having a round cut is part of my culture } & Yes & $8 \%(28)$ & $15 \%(58)$ & $38 \%(33)$ & \multirow[t]{3}{*}{$<.001$} & $14 \%(119)$ & $10.5 \%(51)$ & \multirow[t]{3}{*}{$<.001$} \\
\hline & No & $69 \%(247)$ & $63 \%(245)$ & $47 \%(41)$ & & $64 \%(533)$ & $37 \%(182)$ & \\
\hline & Unsure & $23 \%(83)$ & $22 \%(86)$ & $15 \%$ (13) & & $22 \%(182)$ & $52.5 \%(256)$ & \\
\hline \multirow[t]{3}{*}{ Having a split foreskin proves manhood } & Yes & $25 \%(90)$ & $51 \%(200)$ & $34 \%(29)$ & \multirow[t]{3}{*}{$<.001$} & $38 \%(319)$ & $18 \%(80)$ & \multirow[t]{3}{*}{$<.001$} \\
\hline & No & $32 \%(114)$ & $19 \%(72)$ & $30 \%(26)$ & & $26 \%(212)$ & $18 \%(79)$ & \\
\hline & Unsure & $43 \%(153)$ & $30 \%(116)$ & $36 \%(31)$ & & $36 \%(300)$ & $63 \%(274)$ & \\
\hline \multirow[t]{3}{*}{ Having a round cut proves manhood } & Yes & $24 \%(87)$ & $44 \%(173)$ & $51 \%(44)$ & \multirow[t]{3}{*}{$<.001$} & $36 \%(304)$ & $22 \%(107)$ & \multirow[t]{3}{*}{$<.001$} \\
\hline & No & $31 \%(113)$ & $19 \%(74)$ & $23 \%(20)$ & & $25 \%(207)$ & $18 \%(87)$ & \\
\hline & Unsure & $45 \%(161)$ & $37 \%(142)$ & $26 \%(23)$ & & $39 \%(326)$ & $60 \%(288)$ & \\
\hline \multirow[t]{3}{*}{ Men with a split foreskin are respected by their peers } & Yes & $18 \%(65)$ & $35 \%(135)$ & $29 \%(25)$ & \multirow[t]{3}{*}{$<.001$} & $27 \%(225)$ & $7 \%(35)$ & \multirow[t]{3}{*}{$<.001$} \\
\hline & No & $29 \%(107)$ & $32 \%(124)$ & $40 \%(34)$ & & $32 \%(265)$ & $11 \%(53)$ & \\
\hline & Unsure & $53 \%(191)$ & $33 \%(130)$ & $31 \%(27)$ & & $41 \%(348)$ & $82 \%(396)$ & \\
\hline \multirow[t]{3}{*}{ Men with a round cut are respected by their peers } & Yes & $17 \%(61)$ & $31 \%(122)$ & $42 \%(36)$ & \multirow[t]{3}{*}{$<.001$} & $26 \%(219)$ & $11.5 \%(56)$ & \multirow[t]{3}{*}{$<.001$} \\
\hline & No & $28 \%(102)$ & $31 \%(120)$ & $32 \%(28)$ & & $30 \%(250)$ & $11 \%(55)$ & \\
\hline & Unsure & $55 \%(198)$ & $38 \%(148)$ & $26 \%(23)$ & & $44 \%(360)$ & $77.5 \%(378)$ & \\
\hline \multirow[t]{3}{*}{ Having a split foreskin is forbidden by my religion } & Yes & $23 \%(82)$ & $15 \%(59)$ & $12 \%(10)$ & \multirow[t]{3}{*}{$<.001$} & $18 \%(151)$ & $13 \%(63)$ & \multirow[t]{3}{*}{$<.001$} \\
\hline & No & $42 \%(122)$ & $52 \%(205)$ & $55 \%(47)$ & & $45 \%(374)$ & $28 \%(137)$ & \\
\hline & Unsure & 44\% (158) & 33\% (127) & $34 \%(29)$ & & $37 \%$ (314) & $59 \%$ (284) & \\
\hline \multirow[t]{3}{*}{ Having a round cut is forbidden by my religion } & Yes & $22 \%(79)$ & $15 \%(59)$ & $9 \%(8)$ & \multirow[t]{3}{*}{$<.001$} & $18 \%(146)$ & $13 \%(62)$ & \multirow[t]{3}{*}{$<.001$} \\
\hline & No & $35 \%(125)$ & $51 \%(199)$ & $64 \%(55)$ & & $45 \%(379)$ & $29 \%(141)$ & \\
\hline & Unsure & $43 \%(157)$ & $34 \%(131)$ & $27 \%(23)$ & & $37 \%(311)$ & $58 \%(276)$ & \\
\hline \multirow[t]{3}{*}{ Having a split foreskin is forbidden by my custom/culture } & Yes & $18 \%(63)$ & $13 \%(50)$ & $14 \%(12)$ & \multirow[t]{3}{*}{$<.001$} & $15 \%(125)$ & $11.5 \%(54)$ & \multirow[t]{3}{*}{$<.001$} \\
\hline & No & $44 \%(156)$ & $65 \%(250)$ & $64 \%(55)$ & & $56 \%(461)$ & $30 \%(145)$ & \\
\hline & Unsure & $39 \%(139)$ & $22 \%(86)$ & $22 \%(19)$ & & $29 \%(244)$ & $58.5 \%(281)$ & \\
\hline \multirow[t]{3}{*}{ Having a round cut is forbidden by my custom/culture } & Yes & $19 \%(68)$ & $15 \%(58)$ & $11 \%(10)$ & $<.001$ & $16 \%(136)$ & $11.5 \%(55)$ & $<.001$ \\
\hline & No & $43 \%(157)$ & $61 \%(236)$ & $70 \%(61)$ & & $54 \%(454)$ & $30 \%(145)$ & \\
\hline & Unsure & $38 \%$ (136) & $24 \%(95)$ & $18 \%(16)$ & & $30 \%$ (247) & $58.5 \%(280)$ & \\
\hline
\end{tabular}


Table 4 Attitudes and beliefs about foreskin cutting (Continued)

\section{Theme (ii) Foreskin cutting and sexual practice}

\section{A split foreskin decreases sexual pleasure for a man}

A round cut decreases sexual pleasure for a man

Sex lasts longer for men who have a split foreskin

Sex lasts longer for men who have a round cut

Having a split foreskin encourages men to have more sexual partners

Having a round cut encourages men to have more sexual partners

Women prefer to have sex with a man who has a split foreskin

Women prefer to have sex with a man who has a round cut

\section{Theme (iii) foreskin cutting and sexual health}

Men with a split foreskin do not need to use condoms to protect them from STIS \& HIV

Men with a round cut do not need to use condoms to protect them from STIS \& HIV

$\begin{array}{llll}\text { Yes } & 13 \%(47) & 16 \%(62) & 8 \%(7) \\ \text { No } & 26 \%(95) & 50 \%(194) & 50 \%(42) \\ \text { Unsure } & 61 \%(220) & 34 \%(135) & 43 \%(37) \\ \text { Yes } & 14 \%(51) & 14 \%(56) & 15 \%(13) \\ \text { No } & 26 \%(93) & 43 \%(166) & 53 \%(46) \\ \text { Unsure } & 60 \%(218) & 43 \%(168) & 32 \%(28) \\ \text { Yes } & 19 \%(68) & 44 \%(171) & 22 \%(19) \\ \text { No } & 12 \%(42) & 13 \%(52) & 20 \%(17) \\ \text { Unsure } & 69 \%(250) & 43 \%(166) & 58 \%(50) \\ \text { Yes } & 19 \%(67) & 38 \%(145) & 47 \%(41) \\ \text { No } & 1 \%(41) & 12 \%(46) & 14 \%(12) \\ \text { Unsure } & 70 \%(252) & 50 \%(195) & 39 \%(34) \\ \text { Yes } & 28 \%(100) & 41 \%(159) & 25 \%(21) \\ \text { No } & 19 \%(70) & 30 \%(116) & 44 \%(37) \\ \text { Unsure } & 53 \%(192) & 29 \%(113) & 31 \%(26) \\ \text { Yes } & 27 \%(99) & 40 \%(153) & 26 \%(22) \\ \text { No } & 18 \%(67) & 26 \%(102) & 48 \%(41) \\ \text { Unsure } & 54 \%(196) & 34 \%(132) & 27 \%(23) \\ \text { Yes } & 31 \%(112) & 51 \%(200) & 39 \%(34) \\ \text { No } & 10 \%(35) & 7 \%(26) & 11 \%(9) \\ \text { Unsure } & 59 \%(214) & 42 \%(165) & 50 \%(43) \\ \text { Yes } & 31 \%(114) & 49 \%(193) & 50 \%(44) \\ \text { No } & 10 \%(35) & 6 \%(25) & 8 \%(7) \\ \text { Unsure } & 59 \%(213) & 45 \%(175) & 34 \%(37)\end{array}$

Yes $\quad 13 \%(45) \quad 17 \%(65)$

No $\quad 50 \%(181) \quad 61 \%(239)$

Unsure $37 \%(135) \quad 22 \%(88)$

Yes $\quad 14 \%(52) \quad 17 \% 965)$

No $\quad 49 \%(176) \quad 61 \%(237)$

Unsure $37 \%(132) \quad 23 \%(89)$
11\% (9)

$69 \%(59)$

$20 \%(17)$

9\% (8)

$72 \%(61)$

$19 \%(16)$

\begin{tabular}{|c|c|c|c|}
\hline \multirow[t]{3}{*}{$<.001$} & 14\% (116) & $9 \%(46)$ & \multirow[t]{3}{*}{$<.001$} \\
\hline & 39\% (331) & $22 \%(104)$ & \\
\hline & 47\% (392) & $69 \%$ (330) & \\
\hline \multirow[t]{3}{*}{$<.001$} & $14 \%(120)$ & $10 \%(48)$ & \multirow[t]{3}{*}{$<.001$} \\
\hline & $36 \%$ (305) & $22 \%(104)$ & \\
\hline & $49 \%(414)$ & $68 \%$ (329) & \\
\hline \multirow[t]{3}{*}{$<.001$} & $31 \%$ (258) & $9.5 \%(46)$ & \multirow[t]{3}{*}{$<.001$} \\
\hline & 13\% (111) & $10.5 \%(51)$ & \\
\hline & $56 \%(466)$ & $80 \%$ (387) & \\
\hline \multirow[t]{3}{*}{$<.001$} & $30 \%(253)$ & $13 \%(63)$ & \multirow[t]{3}{*}{$<.001$} \\
\hline & $12 \%(99)$ & $8.5 \%(40)$ & \\
\hline & $58 \%(481)$ & $78.5 \%$ (375) & \\
\hline \multirow[t]{3}{*}{$<.001$} & $34 \%$ (280) & $17 \%(82)$ & \multirow[t]{3}{*}{$<.001$} \\
\hline & $27 \%$ (223) & $21.5 \%(102)$ & \\
\hline & $40 \%$ (331) & $61.5 \%$ (294) & \\
\hline \multirow[t]{3}{*}{$<.001$} & $33 \%$ (274) & 19\% (90) & \multirow[t]{3}{*}{$<.001$} \\
\hline & $25 \%(210)$ & $21 \%(100)$ & \\
\hline & $42 \%$ (351) & $60 \%$ (281) & \\
\hline \multirow[t]{3}{*}{$<.001$} & $41 \%$ (346) & $15 \%(72)$ & \multirow[t]{3}{*}{$<.001$} \\
\hline & $8 \%(70)$ & $11 \%(52)$ & \\
\hline & $50 \%(422)$ & 74\% (358) & \\
\hline \multirow[t]{3}{*}{$<.001$} & $42 \%(351)$ & $22 \%(106)$ & \multirow[t]{3}{*}{$<.001$} \\
\hline & $8 \%(67)$ & 8\% (38) & \\
\hline & $50 \%(425)$ & $70 \%$ (338) & \\
\hline \multirow[t]{3}{*}{$<.001$} & $14 \%$ (119) & $10 \%(48)$ & \multirow[t]{3}{*}{$<.001$} \\
\hline & $57 \%$ (479) & $50 \%(242)$ & \\
\hline & $29 \%(240)$ & 40\% (195) & \\
\hline \multirow[t]{3}{*}{$<.001$} & $15 \%$ 9125) & $10 \%(47)$ & \multirow[t]{3}{*}{$<.001$} \\
\hline & $57 \%(474)$ & $51 \%(246)$ & \\
\hline & $28 \%$ (237) & $39 \%$ (190) & \\
\hline
\end{tabular}


Table 4 Attitudes and beliefs about foreskin cutting (Continued)

\begin{tabular}{|c|c|c|c|c|c|c|c|c|}
\hline \multirow[t]{3}{*}{ Men with a split foreskin can become infected with HIV } & Yes & $59 \%(211)$ & $64 \%(251)$ & $65 \%(56)$ & .015 & $63 \%(518)$ & $45 \%(219)$ & $<.001$ \\
\hline & No & $6 \%(20)$ & $10 \%(39)$ & $9 \%(8)$ & & $8 \%(67)$ & $10 \%(50)$ & \\
\hline & Unsure & $36 \%(127)$ & $26 \%(100)$ & $26 \%(22)$ & & $30 \%(249)$ & $44 \%(213)$ & \\
\hline \multirow[t]{3}{*}{ Men with a round cut can become infected with HIV } & Yes & $58 \%(209)$ & $64 \%(250)$ & $68 \%(60)$ & .059 & $62 \%(519)$ & $41 \%(198)$ & $<.001$ \\
\hline & No & $7 \%(26)$ & $9 \%(36)$ & $10 \%(9)$ & & $8 \%(71)$ & $13 \%(64)$ & \\
\hline & Unsure & $35 \%(126)$ & $27 \%(106)$ & $22 \%(19)$ & & $30 \%(251)$ & $46 \%(220)$ & \\
\hline \multirow[t]{3}{*}{ A split foreskin reduces the risk of becoming infected with HIV } & Yes & $31 \%(112)$ & $37 \%(145)$ & $33 \%(28)$ & .324 & $34 \%(285)$ & $27 \%(130)$ & $<.001$ \\
\hline & No & $25 \%(92)$ & $26 \%(101)$ & $28 \%(24)$ & & $26 \%(217)$ & $22 \%(105)$ & \\
\hline & Unsure & $44 \%(157)$ & $37 \%(142)$ & $39 \%(34)$ & & $40 \%(333)$ & $51 \%(248)$ & \\
\hline \multirow[t]{3}{*}{ A round cut reduces the risk of becoming infected with HIV } & Yes & $35 \%(126)$ & $39 \%(153)$ & $36 \%(32)$ & .813 & $37 \%(311)$ & $33.5 \%(162)$ & $<.001$ \\
\hline & No & $26 \%(93)$ & $25 \%(98)$ & $24 \%(21)$ & & $25 \%(212)$ & $17 \%(82)$ & \\
\hline & Unsure & $39 \%(141)$ & $36 \%(141)$ & $40 \%(35)$ & & $38 \%(317)$ & $49.5 \%(239)$ & \\
\hline \multicolumn{9}{|l|}{ Theme (iv) foreskin cutting and safety } \\
\hline \multirow{3}{*}{$\begin{array}{l}\text { It is safe to use the same blade or razor to split or remove the foreskin of } \\
\text { many men at one time }\end{array}$} & Yes & $5 \%(17)$ & $8 \%(30)$ & $6 \%(5)$ & $<.001$ & $6 \%(52)$ & $3 \%(16)$ & $<.001$ \\
\hline & No & $81 \%(293)$ & $87 \%(339)$ & $89 \%(77)$ & & $85 \%(709)$ & $75 \%(365)$ & \\
\hline & Unsure & $14 \%(51)$ & $5 \%(21)$ & $5 \%(4)$ & & $9 \%(76)$ & $21 \%(104)$ & \\
\hline \multirow[t]{3}{*}{ Splitting the foreskin in a village by a friend or relative is a safe procedure } & Yes & $8 \%(27)$ & $15 \%(60)$ & $17 \%(15)$ & .005 & $12 \%(102)$ & $5.5 \%(26)$ & $<.001$ \\
\hline & No & $67 \%(237)$ & $64 \%(245)$ & $65 \%(55)$ & & $65 \%(537)$ & $63.5 \%(297)$ & \\
\hline & Unsure & $26 \%(91)$ & $21 \%(80)$ & $18 \%(15)$ & & $23 \%(186)$ & $31 \%(146)$ & \\
\hline \multirow{3}{*}{$\begin{array}{l}\text { Removing the foreskin in a village by a friend or relative is a safe } \\
\text { procedure }\end{array}$} & Yes & $8 \%(27)$ & $12 \%(46)$ & $17 \%(15)$ & .043 & $11 \%(88)$ & $6 \%(30)$ & $<.001$ \\
\hline & No & $67 \%(243)$ & $66 \%(258)$ & $66 \%(57)$ & & $64 \%$ (558) & $61.5 \%(296)$ & \\
\hline & Unsure & $25 \%(92)$ & $22 \%(87)$ & $17 \%(15)$ & & $23 \%$ (194) & $32.5 \%(157)$ & \\
\hline \multirow{3}{*}{$\begin{array}{l}\text { Having a round cut by a doctor or nurse in a clinic or hospital is a safe } \\
\text { procedure }\end{array}$} & Yes & $83 \%$ (298) & $92 \%(360)$ & $88 \%(77)$ & .005 & $88 \%(735)$ & $71 \%(342)$ & $<.001$ \\
\hline & No & $3 \%(10)$ & $2 \%(7)$ & $3 \%(3)$ & & $2 \%(20)$ & $5 \%(23)$ & \\
\hline & Unsure & $14 \%(51)$ & $6 \%(25)$ & $8 \%(7)$ & & $10 \%(83)$ & $24 \%(118)$ & \\
\hline \multicolumn{9}{|l|}{ Theme (v) foreskin cutting and socio-cultural beliefs } \\
\hline \multirow{3}{*}{$\begin{array}{l}\text { Allowing blood to flow when the foreskin is split or removed is important } \\
\text { in my custom/culture }\end{array}$} & Yes & $21 \%(76)$ & $26 \%(102)$ & $30 \%(26)$ & .067 & $24 \%(204)$ & $7 \%(33)$ & $<.001$ \\
\hline & No & $42 \%(151)$ & $46 \%(180)$ & $38 \%(33)$ & & $43 \%(364)$ & $25 \%(121)$ & \\
\hline & Unsure & $40 \%(133)$ & $28 \%(111)$ & $32 \%(28)$ & & $32 \%(272)$ & $68 \%(326)$ & \\
\hline \multirow{3}{*}{$\begin{array}{l}\text { A man needs to eat special food in the days after having his foreskin split } \\
\text { or removed }\end{array}$} & Yes & $46 \%(166)$ & $71 \%(278)$ & $61 \%(53)$ & $<.001$ & $59 \%(497)$ & $25 \%(123)$ & $<.001$ \\
\hline & No & $7 \%(26)$ & $11 \%(42)$ & $18 \%(16)$ & & $10 \%(84)$ & $10 \%(47)$ & \\
\hline & Unsure & $47 \%(170)$ & $18 \%(70)$ & $21 \%(18)$ & & $31 \%(258)$ & $65 \%(311)$ & \\
\hline
\end{tabular}


Table 4 Attitudes and beliefs about foreskin cutting (Continued)

\begin{tabular}{|c|c|c|c|c|c|c|c|c|}
\hline \multirow{3}{*}{$\begin{array}{l}\text { A man needs to reduce the amount of water he drinks in the days after } \\
\text { having his foreskin split or removed }\end{array}$} & Yes & $52 \%(188)$ & $85 \%(333)$ & $72 \%(63)$ & $<.001$ & $69 \%(584)$ & $22 \%(107)$ & $<.001$ \\
\hline & No & $7 \%(26)$ & $5 \%(19)$ & $13 \%(11)$ & & $7 \%(56)$ & $10 \%(49)$ & \\
\hline & Unsure & $41 \%(148)$ & $10 \%(41)$ & $15 \%(13)$ & & $24 \%(202)$ & $68 \%(327)$ & \\
\hline \multirow[t]{3}{*}{ A man needs to avoid women in the days after having his foreskin split or removed } & Yes & $68 \%(245)$ & $91 \%(355)$ & $90 \%(78)$ & $<.001$ & $81 \%(678)$ & $48 \%(230)$ & $<.001$ \\
\hline & No & $4 \%(16)$ & $3 \%(10)$ & $2 \%(2)$ & & $3 \%(28)$ & $4 \%(18)$ & \\
\hline & Unsure & $28 \%(101)$ & $7 \%(27)$ & $8 \%(7)$ & & $16 \%(135)$ & $48 \%(232)$ & \\
\hline \multirow[t]{3}{*}{ A split foreskin makes a man's body grow strong } & Yes & $30 \%(108)$ & $54 \%(213)$ & $43 \%(37)$ & $<.001$ & $43 \%(358)$ & $16 \%(76)$ & $<.001$ \\
\hline & No & $11 \%(39)$ & $9 \%(36)$ & $16 \%(14)$ & & $11 \%(89)$ & $12 \%(56)$ & \\
\hline & Unsure & $59 \%(210)$ & $37 \%(144)$ & $41 \%(35)$ & & $46 \%(389)$ & $72 \%(349)$ & \\
\hline \multirow[t]{3}{*}{ A round cut makes a man's body grow strong } & Yes & $31 \%(111)$ & $53 \%(209)$ & $50 \%(44)$ & .001 & $43 \%(364)$ & $18 \%(86)$ & $<.001$ \\
\hline & No & $9 \%(33)$ & $7 \%(27)$ & $14 \%(12)$ & & $9 \%(72)$ & $11 \%(52)$ & \\
\hline & Unsure & $60 \%(217)$ & $40 \%(156)$ & $36 \%(32)$ & & $48 \%(405)$ & $71 \%(343)$ & \\
\hline \multirow[t]{3}{*}{ A split foreskin makes the penis grow bigger } & Yes & $31 \%(111)$ & $53 \%(206)$ & $37 \%(32)$ & $<.001$ & $42 \%(349)$ & $11 \%(52)$ & $<.001$ \\
\hline & No & $9 \%(33)$ & $14 \%(55)$ & $19 \%(16)$ & & $12 \%(104)$ & $13 \%(61)$ & \\
\hline & Unsure & $60 \%(217)$ & $33 \%(131)$ & $44 \%(38)$ & & $46 \%(386)$ & $76 \%(369)$ & \\
\hline \multirow[t]{3}{*}{ A round cut makes the penis grow bigger } & Yes & $31 \%(112)$ & $48 \%(189)$ & $42 \%(37)$ & $<.001$ & $40 \%(338)$ & $14 \%(68)$ & $<.001$ \\
\hline & No & $10 \%(35)$ & $14 \%(54)$ & $22 \%(19)$ & & $13 \%(108)$ & $11.5 \%(55)$ & \\
\hline & Unsure & $59 \%(214)$ & $38 \%(149)$ & $36 \%$ (32) & & 47\% (395) & $74.5 \%$ (358) & \\
\hline
\end{tabular}


Table 5 Acceptability of male circumcision for self and male child for uncut, longitudinal cut and round cut men

\begin{tabular}{|c|c|c|c|c|c|}
\hline & & Uncut men & $\begin{array}{l}\text { Longitudinal } \\
\text { cut men }\end{array}$ & $\begin{array}{l}\text { Round } \\
\text { cut men }\end{array}$ & p-value \\
\hline & & $\%(n) \wedge$ & $\%(n)$ & $\%(n)$ & \\
\hline Would have foreskin completely removed if it had a health benefit & Yes & $76(269)$ & $88(278)$ & & $<.001$ \\
\hline & Maybe & $12(45)$ & 0 & & \\
\hline & No & $12(42)$ & $12(38)$ & & \\
\hline Would have foreskin completely removed if it reduced the risk of getting HIV & Yes & $71(250)$ & $84(258)$ & & $<.001$ \\
\hline & Maybe & $13(46)$ & 0 & & \\
\hline & No & $15(55)$ & $16(49)$ & & \\
\hline Preferred place to have foreskin removed & Hospital/clinic & $95(312)$ & $97(247)$ & & .26 \\
\hline & Others & $3(9)$ & $2(5)$ & & \\
\hline & Not sure & $2(8)$ & $1(2)$ & & \\
\hline Preferred person to remove foreskin & Health worker & $90(298)$ & $95(292)$ & & $<.01$ \\
\hline & Other & $4(14)$ & $3(10)$ & & \\
\hline & $\begin{array}{l}\text { Don't know } \\
\text { /not want MC }\end{array}$ & $6(19)$ & $1(4)$ & & \\
\hline Planning to remove foreskin & Yes & $64(229)$ & $51(163)$ & & $<.001$ \\
\hline & Maybe & $14(50)$ & $26(84)$ & & \\
\hline & No & $22(78)$ & $22(70)$ & & \\
\hline Recommend foreskin removal to friends & Yes & $64(210)$ & $64(209)$ & $89(57)$ & $<.001$ \\
\hline & No & $36(116)$ & $36(116)$ & $11(7)$ & \\
\hline Would have the foreskin removed from male child if it had a health benefit & Yes & $86(260)$ & $92(280)$ & $95(58)$ & $<.05$ \\
\hline & No & $14(43)$ & $8(26)$ & $5(3)$ & \\
\hline Would have the foreskin removed from male child if it reduced the risk of HIV or STls & Yes & $87(250)$ & $93(285)$ & $91(53)$ & $<.05$ \\
\hline & No & $13(38)$ & $7(20)$ & $9(5)$ & \\
\hline
\end{tabular}

${ }^{\wedge}$ Totals are not the same for all characteristics. Some participants did not answer all questions.

study [65] and qualitative findings showing PNG men to be generally in favour of MC for HIV prevention [46]. Further, men with an existing longitudinal cut were overwhelmingly in favour of having the remnant foreskin removed if it reduced the risk of HIV infection. Most of

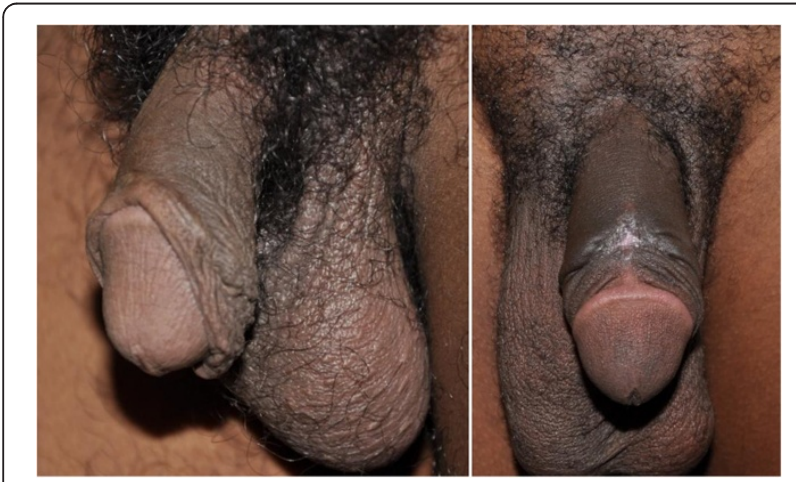

Figure 2 Longitudinal Foreskin cut: Variant (i) Foreskin cut but still partially covers the glans penis; Variant (ii) Foreskin cut and remains loose behind the glans penis. these men had their longitudinal cut in a community setting, but almost all stated they would prefer to have the removal procedure conducted in a health facility by a health professional which they considered a safer option. The high proportion of men willing to have MC is similar to studies in high HIV prevalence settings in Africa (median 65\%) but somewhat greater than studies in other moderate prevalence settings, such as India (58\%), Thailand (14\% and $25 \%$ before and after information) and Dominican Republic (29\% and 67\% before and after information) $[13,40,41,43]$. Methodology, study population, HIV prevalence and socio-cultural context are so different across these studies that comparisons are hard to interpret. Moreover men in these studies were categorised in a circumcised - uncircumcised dichotomy, making interpretation even more difficult for the PNG context where the longitudinal cut is the major form of cutting. However, these studies do reflect the need to investigate understandings and cultural contexts of specific populations to inform if, or how, MC may be a part of the local response to HIV.

MC for children was viewed positively. More than $90 \%$ of men and three quarters of women stated they would 
remove the foreskin of their child if it had a health benefit and/or reduced the risk of HIV. These rates are similar to parents in some high prevalence African settings and provide some of the first evidence about parents' willingness to circumcise their sons in a moderate HIV setting [13]. This provides a unique challenge to the PNG health system that struggles to provide even basic primary health care services for the majority of the population. There are only 0.5 doctors and 5 nurses/midwives per 10000 people in PNG and only 39\% of births are supervised by skilled birth attendants [73,74]. Having a large number of adults, adolescents or infants present for MC would require considerable training, infrastructure and resource allocation across the entire health system.

Specific attitudes and beliefs documented in this study have direct relevance for policy makers. When given the ability to respond yes, no, or unsure to statements about foreskin cutting it was common for around a third of men and often more than half of women responded 'unsure'. Although this high level of uncertainly may be of concern to some service providers or policy makers, it reflects the dynamic socio-cultural context in PNG and that many people are aware of foreskin cutting but may not have fixed attitudes or beliefs towards foreskin cutting. This provides an opportunity for public health campaigns, as called for by Kelly et al. [46], to provide accurate information in a culturally sensitive way that builds on the strength of culture, rather than destroying it. In a country where one's culture and religion is so explicitly referred to in everyday life, it is important to note that few men and women stated foreskin cutting was forbidden by their custom/tradition or religion. Further, none of the beliefs about culture, religion or sexual practice documented in this study contradict the positive views of men and parents towards $\mathrm{MC}$, or the appropriateness of providing $\mathrm{MC}$ services in this setting.

It is pleasing to note that the majority of both men and women believe men with a cut (or removed) foreskin still need to use condoms to prevent STI and HIV. However, of concern is one quarter of men and $40 \%$ of women stated they were unsure. This requires current public health messages about STI and HIV prevention to emphasise that condoms are for everyone regardless of a man's foreskin cutting status. It is also encouraging that almost all men and women think it is unsafe to use the same blade to cut many men. This is likely to be due to cultural beliefs about the contagion potential of blood re-enforced by public HIV prevention messages about the danger of sharing tools for body cutting, tattooing or scarification practices [75]. Nevertheless, 19\% of men and 52\% of women were not sure or do not think it is necessary to avoid sexual contact in the days after the foreskin cut, highlighting the need for more specific MC education.

As in other low-moderate HIV burden settings with heterosexual transmission, a key challenge is how to expand existing clinical MC services, increase the safety of existing community foreskin cutting practices and/or introduce new MC services appropriate to local contexts. Decision makers must consider programs that deliver the greatest epidemiological and public health impact while being responsive to diverse socio-cultural practices and health service capacity $[33,45,46]$. In this context, researchers and policy makers in PNG are actively considering international and local evidence to inform policy making and future research [76,77].

The major strength of this study was that it was a partnership between PNG and Australian universities and two large resource companies across four provinces at sites where people from across PNG come to study or work. This allowed access to a great diversity of men and women who provided data on traditional and contemporary foreskin cutting practices and beliefs. However, only some major descriptive analysis of this large quantitative data set on foreskin cutting practices and beliefs could be presented in this paper. Further more detailed analyses of quantitative data and findings from qualitative interviews and focus group discussions will be published separately. Given the hyper-diversity of having more than 800 languages, and thus diverse sets of beliefs and practices in the country, this study provides a limited, although valuable snapshot of current foreskin cutting and the acceptability of $\mathrm{MC}$ in PNG.

\section{Conclusion}

This study considerably expands the evidence base of current foreskin cutting practices in this moderate HIV prevalence setting. The major form of foreskin cut is the longitudinal cut along the dorsal surface resulting in the remnant foreskin hanging from the ventral surface of the penis. In most cases this totally exposes the glans penis and results in a remnant foreskin that is dry, reduced in size and with the inner surface visually similar to the outer surface. Foreskin removal (MC), from both uncut men and men with an existing longitudinal cut was considered appropriate and acceptable by most men and women in this study. Potential MC services will need to be responsive to the great diversity of local socio-cultural beliefs and practices and existing health service constraints. Research evidence of the protection conferred by longitudinal cuts is urgently needed to inform HIV prevention strategies in this setting. This study provides vital evidence on current foreskin cutting beliefs and practices and the implications for the acceptability of MC for HIV prevention in PNG. It thus enables more effective planning of HIV prevention in PNG and other populations with dynamic and varied sociocultural foreskin cutting practices. 


\section{Additional files}

\section{Additional file 1: Figure S1. Male Questionnaire in English.}

Additional file 2: Figure S2. Female Questionnaire in English.

\section{Competing interests}

The authors declare there they have no competing interests.

\section{Authors' contributions}

DM and WJM conceived, designed and coordinated the study and drafted the manuscript. RT, TM, CM, FF, MRM, MW, KB participated in the design and coordination of the study; collected, managed and analysed data; helped draft and revise the manuscript. RM and JK managed, analysed and interpreted data and help to draft and revise the manuscript. All authors have read and approved the final manuscript.

\section{Acknowledgements}

We wish to thank the study participants, local steering group members and all members of the 'Acceptability of Male Circumcision for HIV Prevention in Papua New Guinea' study. A special thanks to Divine Word University, Pacific Adventist University, James Cook University, Higaturu Oil Palms and Barrick Gold (Porgera Joint Venture) for partnering in the study, including in-kind support. Thanks also to the Papua New Guinea National Department of Health/Asian Development Bank HIV Prevention in Rural Enclaves Project for intellectual and logistic support throughout. Capacity building workshops and ongoing support throughout the study were facilitated by Associate Professor Petra Buttner from James Cook University; Ethics approvals were granted by Papua New Guinea National AIDS Council, Pacific Adventist University, Divine Word University and James Cook University and endorsed by Provincial AIDS Committees of Enga, Oro and Madang Provinces and National Capital District, all for which we are grateful. The study was funded by National Health and Medical Research Project Grant 601003 and Capacity Building Workshop for PNG staff funded by Australian Leadership Award Fellowships Agreement Number 59019.

\section{Author details}

'School of Medicine and Dentistry, James Cook University, McGregor Road, Smithfield, Cairns 4878, Queensland, Australia. ${ }^{2}$ School of Health Science, Pacific Adventist University, Port Moresby, National Capital District, Papua New Guinea. ${ }^{3}$ Deputy Vice Chancellor, Pacific Adventist University, Port Moresby, National Capital District, Papua New Guinea. ${ }^{4}$ Faculty of Health Science, Divine Word University, Madang, Madang Province, Papua New Guinea. ${ }^{5}$ Global Health Unit, University of Montreal Hospital Research Centre, Montreal, Quebec, Canada. ${ }^{6}$ School of Arts and Social Science, James Cook University, Cairns, Queensland, Australia. ${ }^{7}$ Rural Primary Health Services Delivery Project, National Department of Health, Port Moresby, Papua New Guinea. ${ }^{8}$ School of Public Health, Tropical Medicine and Rehabilitation Science, James Cook University, Cairns, Queensland, Australia. ${ }^{9}$ Tropical Health Solutions, Townsville, Australia. ${ }^{10}$ Kirby Institute, University of New South Wales, Sydney, New South Wales, Australia.

Received: 9 May 2013 Accepted: 5 September 2013

Published: 9 September 2013

\section{References}

1. Auvert B, Taljaard D, Lagarde E, Sobngwi-Tambekou J, Sitta R, Puren A: Randomized, controlled intervention trial of male circumcision for reduction of HIV infection risk: the ANRS 1265 Trial. PLoS Med 2005, 2(11):e298.

2. Bailey RC, Moses S, Parker CB, Agot K, Maclean I, Krieger JN, Williams CF, Campbell RT, Ndinya-Achola JO: Male circumcision for HIV prevention in young men in Kisumu, Kenya: a randomised controlled trial. Lancet 2007, 369(9562):643-656.

3. Gray RH, Kigozi G, Serwadda D, Makumbi F, Watya S, Nalugoda F, Kiwanuka N, Moulton LH, Chaudhary MA, Chen MZ, et al: Male circumcision for HIV prevention in men in Rakai, Uganda: a randomised trial. Lancet 2007, 369(9562):657-666.

4. Weiss HA, Quigley MA, Hayes RJ: Male circumcision and risk of HIV infection in sub-Saharan Africa: a systematic review and meta-analysis. AIDS 2000, 14(15):2361-2370.
5. Siegfried N, Muller M, Deeks JJ, Volmink J: Male circumcision for prevention of heterosexual acquisition of HIV in men. Cochrane Database Syst Rev 2009, 2, CD003362.

6. Nagelkerke NJ, Moses S, de Vlas SJ, Bailey RC: Modelling the public health impact of male circumcision for HIV prevention in high prevalence areas in Africa. BMC Infec Dis 2007, 7:16.

7. Londish GJ, Murray JM: Significant reduction in HIV prevalence according to male circumcision intervention in sub-Saharan Africa. Int J Epidemiol 2008, 37(6):1246-1253.

8. Auvert B, Taljaard D, Rech D, Lissouba P, Singh B, Shabangu D: Effect of the Orange Farm (South Africa) male circumcision roll-out (ANRS-12126) on the spread of HIV. In 6th IAS Conference on HIV Pathogenesis, Treatment and Prevention: 20 July 2011. Rome, Italy: International AIDS Society; 2011.

9. WHO: [Press Release] WHO and UNAIDS announce Recommendations from Expert Meeting on Male Circumcision for HIV Prevention. Geneva: WHO; 2007.

10. Nnko S, Washija R, Urassa M, Boerma JT: Dynamics of male circumcision practices in northwest Tanzania. Sex Transm Dis 2001, 28(4):214-218.

11. Jayeoba O, Dryden-Peterson S, Okui L, Smeaton L, Magetse J, Makori L, Modikwa V, Mogodi M, Plank R, Lockman S: Acceptability of male circumcision among adolescent boys and their parents, Botswana. AIDS Behav 2012, 16(2):340-349.

12. Iliyasu Z, Abubakar IS, Sani IH, Jibo AM, Karaye IM, Salihu HM, Aliyu MH: Male circumcision and HIV risk behavior among University students in Northern Nigeria. Am J Mens Health 2012, 25:401-406.

13. Westercamp N, Bailey RC: Acceptability of male circumcision for prevention of HIV/AIDS in sub-Saharan Africa: a review. AIDS Behav 2007 11(3):341-355.

14. Lukobo MD, Bailey RC: Acceptability of male circumcision for prevention of HIV infection in Zambia. AIDS Care 2007, 19(4):471-477.

15. Ngalande RC, Levy J, Kapondo CP, Bailey RC: Acceptability of male circumcision for prevention of HIV infection in Malawi. AIDS Behav 2006, 10(4):377-385.

16. Scott BE, Weiss HA, Viljoen Jl: The acceptability of male circumcision as an HIV intervention among a rural Zulu population, Kwazulu-Natal, South Africa. AIDS Care 2005, 17(3):304-313.

17. Mattson CL, Bailey RC, Muga R, Poulussen R, Onyango T: Acceptability of male circumcision and predictors of circumcision preference among men and women in Nyanza Province, Kenya. AIDS Care 2005, 17(2):182-194.

18. Halperin DT, Fritz K, McFarland W, Woelk G: Acceptability of adult male circumcision for sexually transmitted disease and HIV prevention in Zimbabwe. Sex Transm Dis 2005, 32(4):238-239.

19. Lagarde E, Dirk T, Puren A, Reathe RT, Bertran A: Acceptability of male circumcision as a tool for preventing HIV infection in a highly infected community in South Africa. AIDS 2003, 17(1):89-95.

20. Kebaabetswe P, Lockman S, Mogwe S, Mandevu R, Thior I, Essex M, Shapiro RL: Male circumcision: an acceptable strategy for HIV prevention in Botswana. Sex Trans Infect 2003, 79(3):214-219.

21. Bailey RC, Muga R, Poulussen R, Abicht H: The acceptability of male circumcision to reduce HIV infections in Nyanza Province, Kenya. AIDS Care 2002, 14(1):27-40.

22. WHO, UNAIDS: Joint Strategic Action Framework to Accelerate the Scale-Up of Voluntary Medical Male Circumcision for HIV Prevention in Eastern and Southern Africa (2012-2016). Geneva: UNAIDS; 2011.

23. WHO, UNAIDS: Progress in Scale-up of Male Circumcision for HIV prevention in Eastern and Southern Africa. Geneva: WHO; 2011.

24. WHO: Use of devices for adult male circumcision in public health HIV prevention programmes - Conclusions of the WHO Technical Advisory Group on Innovations in Male Circumcision. Geneva: WHO; 2012.

25. Westercamp M, Agot KE, Ndinya-Achola J, Bailey RC: Circumcision preference among women and uncircumcised men prior to scale-up of male circumcision for HIV prevention in Kisumu, Kenya. AIDS Care 2012, 24(2):157-166.

26. Waters E, Stringer E, Mugisa B, Temba S, Bowa K, Linyama D: Acceptability of neonatal male circumcision in Lusaka, Zambia. AIDS Care 2012, 24(1):12-19.

27. Tarimo EA, Francis JM, Kakoko D, Munseri P, Bakari M, Sandstrom E: The perceptions on male circumcision as a preventive measure against HIV infection and considerations in scaling up of the services: a qualitative study among police officers in Dar es Salaam, Tanzania. BMC Publ Health 2012, 12(1):529.

28. Sheldon WR, Nhemachena T, Blanchard K, Chipato T, Ramjee G, Trussell J, McCulloch CE, Blum M, Harper CC: Male circumcision for HIV prevention: clinical practices and attitudes among healthcare providers in South Africa and Zimbabwe. Sex Transm Dis 2012, 39(7):567-575. 
29. Ngo TD, Obhai G: Male circumcision uptake, postoperative complications, and satisfaction associated with mid-level providers in rural Kenya. HIV/AIDS - Research and Palliative Care 2012, 2012:37-43.

30. Mavhu W, Hatzold K, Laver SM, Sherman J, Tengende BR, Mangenah C, Langhaug LF, Hart G, Cowan FM: Acceptability of early infant male circumcision as an HIV prevention intervention in Zimbabwe: a qualitative perspective. PLoS One 2012, 7(2):e32475.

31. Lundsby K, Draebel T, Wolf Meyrowitsch D: 'It brought joy in my home as in the area of my wife'. How recently circumcised adult men ascribe value to and make sense of male circumcision. Global Public Health 2012, 7(4):352-366.

32. Kuznik A, Lamorde M, Sekavuga DB, Picho B, Coutinho A: Medical male circumcision for HIV/AIDS prevention in Uganda - the cost of disposable versus re-usable circumcision kits. Trop Doct 2012, 42(1):5-7.

33. Gasasira RA, Sarker M, Tsague L, Nsanzimana S, Gwiza A, Mbabazi J, Karema C, Asiimwe A, Mugwaneza P: Determinants of circumcision and willingness to be circumcised by Rwandan Men, 2010. BMC Publ Health 2012, 12(1):134.

34. Andersson N, Cockcroft A: Male circumcision, attitudes to HIV prevention and HIV status: a cross-sectional study in Botswana, Namibia and Swaziland. AIDS Care 2012, 24(3):301-309.

35. Siegler AJ, Mbwambo JK, Diclemente RJ: Acceptability of medical male circumcision and improved instrument sanitation among a traditionally circumcising group in East Africa. AIDS Behav 2012, 16(7):1846-1852.

36. Sawires SR, Dworkin SL, Fiamma A, Peacock D, Szekeres G, Coates TJ: Male circumcision and HIV/AIDS: challenges and opportunities. Lancet 2007 369(9562):708-713.

37. Muula AS: Male circumcision to prevent HIV transmission and acquisition: what else do we need to know? AIDS Behav 2007, 11(3):357-363.

38. Peltzer K, Niang Cl, Muula AS, Bowa K, Okeke L, Boiro H, Chimbwete C: Male circumcision, gender and HIV prevention in sub-Saharan Africa: a (social science) research agenda. Sahara J 2007, 4(3):658-667.

39. Kippax S, Holt M, Friedman S: Bridging the social and the biomedical: engaging the social and political sciences in HIV research. J Int AIDS SOC 2011, 14(Suppl 2):S1.

40. Tieu HV, Phanuphak N, Ananworanich J, Vatanparast R, Jadwattanakul T, Pharachetsakul N, Mingkwanrungrueng P, Buajoom R, Teeratakulpisarn S, Teeratakulpisarn $N$, et al: Acceptability of male circumcision for the prevention of HIV among high-risk heterosexual men in Thailand. Sex Transm Dis 2010, 37(6):352-355.

41. Brito MO, Caso LM, Balbuena H, Bailey RC: Acceptability of male circumcision for the prevention of HIV/AIDS in the Dominican Republic. PLoS One 2009, 4(11):e7687.

42. Brito MO, Luna M, Bailey RC: The feasibility and acceptability of male circumcision among men, women, and health providers of the Altagracia Province, Dominican Republic. AIDS Care 2010, 22(12):1530-1535.

43. Madhivanan P, Krupp K, Kulkarni V, Kulkarni S, Klausner JD: Acceptability of male circumcision for HIV prevention among high-risk men in Pune, India. Sex Transm Dis 2011, 38(6):571.

44. Madhivanan P, Krupp K, Chandrasekaran V, Karat SC, Reingold AL, Klausner JD: Acceptability of male circumcision among mothers with male children in Mysore, India. AIDS 2008, 22(8):983-988.

45. Kelly A, Kupul M, Aeno H, Shih P, Naketrumb R, Neo J, Fitzgerald L, Kaldor JM, Siba PM, Vallely A: Why women object to male circumcision to prevent HIV in a moderate-prevalence setting. Qual Health Res 2013, 23(2):180-193.

46. Kelly A, Kupul M, Fitzgerald L, Aeno H, Neo J, Naketrumb R, Siba P, Kaldor J, Vallely A: "Now we are in a different time; various bad diseases have come." Understanding men's acceptability of male circumcision for HIV prevention in a moderate prevalence setting. BMC Publ Health 2012, 12(1):67.

47. National AIDS Council Secretariat: Global AIDS Report: Country Progress Report, Papua New Guinea, Reporting Period January 2010 - December 2011. Port Moresby, Papua New Guinea: National AIDS Council Secretariat; 2012.

48. National AIDS Council Secretariat and Partners PNG: UNGASS 2008 Country Progress Report: Papua New Guinea. Port Moresby: National AIDS Council Secretariat; 2008

49. Vallely A, Page A, Dias S, Siba P, Lupiwa T, Law G, Millan J, Wilson DP, Murray JM, Toole $M$, et al: The prevalence of sexually transmitted infections in Papua New Guinea: A systematic review and meta-analysis. PLoS One 2010, 5(12):e15586-1-e15586-10.

50. National AIDS Council Secretariat: National Research Agenda for HIV\&AIDS in PNG 2008-13. Port Moresby: National AIDS Council Secretariat; 2008.
51. National AIDS Council Secretariat: National HIV and AIDS Research Capacity Building Plan 2010-2013. Port Moresby: National AIDS Council of Papua New Guinea; 2010.

52. National AIDS Council Secretariat: Papua New Guinea National HIV and AIDS Strategy 2011-2015. Port Moresby: National AIDS Council Secretariat; 2010.

53. Hogbin $\mathrm{H}$ : The island of menstruating men: Religion in Wogeo New Guinea. Scranton: Chandler; 1970.

54. Hammar LJ: Sin, Sex and Stigma: A Pacific Response to HIV and AIDS. Wantage: Sean Kingston Publishing; 2010.

55. Caldwell J, Isaac-Toua G: AIDS in Papua New Guinea: situation in the Pacific. J Health Popul Nutr 2002, 20(2):104-111.

56. Hull TH, Budiharsana M: Male circumcision and penis enhancement in Southeast Asia: matters of pain and pleasure. Reprod Health Matters 2001, 9(18):60-67.

57. Hill PS, Tynan A, Law G, Millan J, Browne K, Sauk J, et al: A typology of penile cutting in Papua New Guinea: Results of a modified delphi study among sexual health clinicians. AIDS Care 2011, 24(1):77-86.

58. Kempf W: The politics of incorporation: masculinity, spatiality and modernity among the Ngaing of Papua New Guinea. Oceania 2002, 73(1):56-77.

59. Tuzan D: The Voice of the Tambaran. Berkeley: University of California; 1980.

60. Buchanan HR, Frank R, Couch M, Amos A: The Re-Making of men and penile modification. In Technologies of Sexuality, Identity and Sexual Health. Edited by Manderson L. London: Routledge Press; 2012.

61. Millan J, Yeka W, Obiero W, Pantumari J: HIV/AIDS Behavioural Surveillance Survey: Within High Risk Settings - Papua New Guinea (2006). Port Moresby: National AIDS Council Secretariat, National HIV/AIDS Support Project; 2006.

62. Buchanan HR, Akuani F, Kupe F, Amos A, Sapak K, Be F, Kawage T, Frank R, Couch M: Behavioural Surveillance Research in Rural Development Enclaves in Papua New Guinea: A Study with the Oil Search Limited Workforce. Port Moresby, Papua New Guinea: The National Research Institute; 2011.

63. Kelly A, Kupul M, Man WYN, Nosi S, Lote N, Rawstorne P, Halim G, Ryan C, Worth $\mathrm{H}$ : Askim na save (Ask and understand): People who sell and/or exchange sex in Port Moresby. Key Quantitative Findings. Sydney, Australia: Papua New Guinea Institute of Medical Research and the University of New South Wales; 2011.

64. National Statistical Office of Papua New Guinea: Preliminary Figures: Papua New Guinea Census 2011. Papua New Guinea: Port Moresby; 2011.

65. Tommbe R, Asugeni L, MacLaren D: What Can be Learned about Male Circumcision and HIV Prevention from a Cohort of Students and Staff at a Papua New Guinea University?. Port Moresby, Papua New Guinea: Pacific Adventist University; 2012.

66. Jenkins C, Buchanan-Aruwafu H: Cultures and Contexts Matter: Understanding and Preventing HIV in the Pacific. Manila, Phillipines: Asian Development Bank; 2007.

67. Buchanan-Aruwafu H: An integrated picture: HIV risk and vulnerability in the Pacific. Noumea, New Caledonia: Secretariat of the Pacific Community; 2007.

68. McCoombe SG, Short RV: Potential HIV-1 target cells in the human penis. AIDS 2006, 20(11):1491-1495

69. Kigozi G, Wawer M, Ssettuba A, Kagaayi J, Nalugoda F, Watya S, Mangen FW, Kiwanuka N, Bacon MC, Lutalo T, et al: Foreskin surface area and HIV acquisition in Rakai, Uganda (size matters). AIDS 2009, 23(16):2209-2213.

70. Brown JE, Micheni KD, Grant EM, Mwenda JM, Muthiri FM, Grant AR: Varieties of male circumcision: a study from Kenya. Sex Transm Dis 2001, 28(10):608-612.

71. Thomas AG, Tran BR, Cranston M, Brown MC, Kumar R, Tlelai M: Voluntary medical male circumcision: a cross-sectional study comparing circumcision self-report and physical examination findings in Lesotho. PLoS One 2011, 6(11):e27561.

72. Montgomery C, Pool R: Critically engaging: integrating the social and the biomedical in international microbicides research. J Int AIDS Soc 2011, 14(Suppl 2):S4

73. Rule J, Worth H, Roberts G, Taylor R: Human resource challenges in scaling up the response to HIV in Papua New Guinea. WPSAR 2012, 3(3). 10.5365/ wpsar.2012.3.2.006

74. Dawson A, Howes T, Gray N, Kennedy E: Human resources for health in maternal, neonatal and reproductive health at community level: A profile of Papua New Guinea. Sydney, Australia: Human Resources for Health Knowledge Hub and Burnet Institute; 2011.

75. Kelly A, Kapul M, Aeno H, Neo J, Naketrumb R, Fitzgerald L, Hill P, Kaldor J, Siba $P$, Vallely A: More than just a cut: A qualitative study of penile practices and their relationship to masculinity, sexuality and contagion and their implications for HIV prevention in Papua New Guinea. BMC Int Health Hum Rights 2011, 12(10). 10.1186/1472-698X-12-10. 
76. Vallely A, MacLaren D, on behalf of PNGIMR, UNSW, UQ, DWU, PAU, JCU investigator teams: [Briefing Document] Male circumcision for HIV prevention in Papua New Guinea: a summary of two research projects: briefing document. In National Policy Forum: Male Circumcision on HIV prevention in Papua New Guinea: November 2011. Port Moresby, Papua New Guinea: Papua New Guinea Institute of Medical Research and James Cook University; 2011.

77. Vallely A, MacLaren D: National Policy Forum on Male Circumcision for HIV Prevention in Papua New Guinea: Summary and recommendations for public health. In National Policy Forum on Male Circumcision for HIV Prevention in Papua New Guinea: 2011. Port Moresby, Papua New Guinea: Papua New Guinea Institute of Medical Research and James Cook University; 2011. on behalf of PNGIMR, UNSW, UQ, DWU, PAU, JCU investigator teams.

doi:10.1186/1471-2458-13-818

Cite this article as: MacLaren et al:: Foreskin cutting beliefs and practices and the acceptability of male circumcision for HIV prevention in Papua New Guinea. BMC Public Health 2013 13:818.

\section{Submit your next manuscript to BioMed Central and take full advantage of:}

- Convenient online submission

- Thorough peer review

- No space constraints or color figure charges

- Immediate publication on acceptance

- Inclusion in PubMed, CAS, Scopus and Google Scholar

- Research which is freely available for redistribution 